\title{
Disidencias sexuales en el sistema escolar chileno: represión e invisibilización'
}

Juan Cornejo Espejo"

\section{Resumen}

El objetivo del artículo es dar a conocer los resultados de una investigación llevada a cabo en base al registro de denuncias de discriminación por orientación sexual en el sistema escolar chileno entre los años 2009 y 2015. El catastro de esa información, proveniente de todas las regiones del país, fue elaborado por el Ministerio de Educación de Chile (MINEDUC). De ese catastro se extrajeron las denuncias específicas relativas a discriminación homofóbica. La muestra estuvo conformada por 95 casos, de los cuales el 61,5\% correspondió a mujeres y el 38,4\% a hombres. La metodología empleada privilegió el análisis cualitativo, siguiendo los supuestos de la Teoría Fundamentada. El análisis textual se hizo teniendo como referencia las anotaciones del funcionario del MINEDUC que acogió la denuncia, las cuales fueron conservadas en su forma original, respetando las expresiones y énfasis dados al discurso. Los resultados se presentan a través de dos codificaciones axiales, una de ellas referida a las causas que motivaron la discriminación en los establecimientos denunciados y la segunda a los efectos psico-emocionales, sociales y pedagógicos que ocasionó esa discriminación en las víctimas. En la codificación selectiva, se caracterizaron los elementos constitutivos de la discriminación homofóbica presente en el sistema escolar chileno en el período en estudio. Los principales hallazgos de la investigación muestran que las causales que suscitaron las denuncias estuvieron motivadas por medidas disciplinarias adoptadas por los establecimientos educacionales, consideradas arbitrarias por los denunciantes. Medidas que buscaban reprimir y sancionar a los estudiantes LGBT disidentes sexuales, con el consecuente reforzamiento de la homofobia escolar.

\section{Palabras clave}

Disidencias sexuales - Sistema escolar - Discriminación - Homofobia.

1- Agencia financiadora: Fondecyt Regular 1130501.

2- Universidad Católica del Maule, Talca, Chile.Contacto: jcornejo@ucm.cl 


\title{
Sexual dissidence in the Chilean school system: repression and invisibility'
}

\author{
Juan Cornejo Espejo"
}

\begin{abstract}
The objective of the article is to present the results of an investigation carried out on the basis of the registration of complaints of discrimination based on sexual orientation in the Chilean school system between 2009 and 2015. The cadastre of this information, coming from all the regions of the country, was prepared by the Ministry of Education of Chile (MINEDUC). From that cadastre specific complaints were extracted regarding homophobic discrimination. The sample consisted of 95 cases, of which $61.5 \%$ corresponded to female individuals and $38.4 \%$ to male individuals. The methodology used prioritized the qualitative analysis, following the assumptions of the Grounded Theory. The textual analysis was made with reference to the notes written by the MINEDUC official who accepted the complaint, which were preserved in their original form, without changing any expressions and emphasis given to the discourse. The results are presented through two axial encodings, one referring to the causes that motivated the discrimination in the denounced institutions and the second to the psycho-emotional, social and pedagogical effects that this discrimination caused in the victims. In the selective coding, the constitutive elements of the homophobic discrimination present in the Chilean school system in the period under study were characterized. The main findings of the investigation show that the grounds for the allegations were motivated by disciplinary measures taken by educational establishments, considered arbitrary by the complainants. Measures aimed at suppressing and punishing LGBT students with sexual dissent, with the consequent reinforcement of school homophobia.
\end{abstract}

\section{Keywords}

Sexual dissent - School system - Discrimination - Homophobia.

1- Funding agency: Fondecyt Regular 1130501.

2- Universidad Católica del Maule, Talca, Chile.

Contact: jcornejo@ucm.cl 


\section{Introducción}

La conciencia de que la discriminación -entendida esta como la "acción arbitraria que implica dar un trato de inferioridad a una persona o grupo por motivos que forman parte de su identidad individual y/o social" (CHILE, 2013, p. 8) ${ }^{1}$-, en cualquiera de sus formas alcanza todas las esferas, incluida la escuela, es una idea relativamente reciente en América Latina, particularmente cuando esa discriminación hace referencia a la orientación sexual o las identidades genéricas. Ello, probablemente explicable, por el fuerte sesgo medicalizador-moralizante que pesaba sobre las sexualidades en fuga del orden heteronormativo hasta bien avanzado el siglo XX (ALONSO; MORGADE, 2008).

A este respecto cabe destacar que UNESCO (2012) siguiendo los supuestos de la Comisión Internacional de Juristas (2007) contenidos en los Principios de Yogyakarta define la orientación sexual como:

La capacidad de una persona de sentir una atracción emocional y sexual profunda por, y llevar relaciones intimas y sexuales con, una persona de sexo distinto; con personas del mismo sexo, o con más de un sexo. Por ejemplo, hombres gay viven una atracción sexual por y una capacidad de llevar relaciones Íntimas principalmente con otros hombres. Mujeres lesbianas siente una atracción sexual y tiene una capacidad de llevar relaciones íntimas principalmente con otras mujeres. Personas bisexuales siente atracciones tanto por hombres como mujeres (UNESCO, 2012, p. 6).

En lo que se refiere a la identidad de género UNESCO, en concordancia con lo establecido por el Consejo de Europa (2011), sostiene que esta:

1- La legislación chilena a través de la Ley 20.609, de julio de 2012 especifica lo que entiende por discriminación (ver definición, p. 15-16). Asimismo, entre las numerosas aproximaciones al tema destaca el estudio del CEPESC - Center for Study and Research in Collective Healh, titulado: Diversity in School (2012).
Hace referencia a sentimiento personal profundo y a la experiencia individual de género. Con ello, la identidad de género puede no corresponder con el sexo biológico que se asigna al nacer. Incluye la percepción personal del cuerpo (que puede implicar, por decisión voluntaria, modificación de la apariencia o funcionamiento corporal, a través de recursos médicos, quirúrgicos $\mathrm{u}$ otros medios), y otras expresiones del género, como vestimenta, forma de hablar y comunicarse, entre otras (UNESCO, 2012, p. 6) ${ }^{2}$.

En ese mismo documento se hace referencia a la identidad discrepante, esto es, sujetos cuyos sentimientos y experiencias personales de género no se corresponden con su sexo biológico.

Tradicionalmente se pensaba que la escuela poco tenía que ver con las controversias y luchas por la reivindicación de derechos que se daban en otros campos sociales. A lo más ella era otro de los ámbitos donde la segregación se hacía presente, en tanto institución que segmentaba o restringía las posibilidades de circulación o estancia de sujetos o grupos. Es decir, había poca conciencia de que ella no sólo es portadora y expresión de la discriminación, sino que en su seno se gestan y germinan muchas de las creencias que nutren y refuerzan sus manifestaciones sociales.

En el caso chileno, al igual que en el resto del continente, el heterosexismo, la omisión de la diversidad sexual, la exclusión de las disidencias sexuales y la naturalización de la homofobia hacían parte del cotidiano escolar. La posibilidad de realización eróticoafectivo al margen de los estrechos márgenes

2- Una abundante literatura tanto de organismos internacionales como de distintos gobiernos, así como de connotados(as) investigadores(as) aluden al tema, subrayando el binomio sexo / género como elemento articulador de la definición. Entre el primer grupo destaca el texto del Ministerio de Sanidad, Servicio Social e Igualdad de España (ESPAÑA, 2015). Entre los segundos destacan las producciones de Judith Butler (2012), Beatriz Preciado (2014) y Guacira Lopes Louro, Jane Felipe y Silvana Vilodre Goellner (2013). 
del heterosexismo o el reconocimiento de otras expresiones de la sexualidad humana, prácticamente eran impensadas, tanto por la invisibilización de la sexualidad de niños y adolescentes, como por la sanción que recaía sobre cualquier posible desviación, las que debían ser prontamente reprimidas y anuladas.

En ese contexto la visibilización de la discriminación homofóbica se empieza a configurar en el espacio escolar chileno desde inicios de los años 2000, como consecuencia de la escalada de violencia escolar que comienza a preocupar a las autoridades educacionales. El reconocimiento del problema y la búsqueda de sus causales derivaron en que se tomara conciencia de que una parte importante de esa violencia estaba motivada por la discriminación y el bullying de que eran objeto numerosos estudiantes a lo largo de todo el país.

Sin ser un problema nuevo en el sistema escolar, en las últimas décadas dada la mayor conciencia de vulneración de derechos y visibilidad del problema, el bullying ha tendido a concentrar la atención tanto de autoridades como de especialistas no sólo por los trastornos que ocasiona a la convivencia escolar sino por los efectos nocivos que provoca a la salud psico-emocional de las víctimas, al punto de ser catalogado como un problema de salud pública (AERA, 2013).

Numerosas son las definiciones y abordajes que se ha dado a la problemática, no obstante, todos parecen coincidir en que se trata de "toda forma de maltrato físico, verbal o psicológico que se produce entre escolares de forma reiterada y a lo largo del tiempo" (UNESCO, 2015, p. 15). Es decir, el denominador común de acuerdo con Dan Olweus (1993), psicólogo noruego precursor de los estudios acerca del tema son los comportamientos agresivos reiterados en el tiempo.

Los elementos distintivos del bullying son: la frecuencia (ocurrencia repetida y persistente), la relación desigual de poder entre la víctima y el o los agresores, la intención deliberada de ocasionar daño físico, psicológico o social, y los efectos negativos sobre el desempeño escolar de las víctimas que normalmente se traduce en ausentismo y/o bajo rendimiento. Y si bien es posible reconocer varios tipos de bullying y expresiones del mismo el más nocivo de todos es el bullying homofóbico no sólo por lo extendido del problema a nivel mundial (UNESCO, 2012), sino por la doble victimización de que son objeto muchas de esos estudiantes, violentados por sus pares y también por sus propias familias que se resisten y se avergüenzan de tener un hijo o hija disidente sexual y/o genérico.

Este tipo específico de bullying ha sido definido por UNESCO como: “[...] un tipo específico de violencia escolar que se dirige hacia personas por su orientación sexual y/o identidad de género, percibida o real" (2012, p. 13). En esta misma línea la investigadora española, Raquel Platero señala que:

[...] son aquellos comportamientos violentos por los que un alumno o alumna se expone y/o queda expuesto repetidamente a la exclusión, aislamiento, amenaza, insultos y agresiones por parte de sus iguales, una o varias personas que están en su entorno más próximo, en una relación desigual de poder, donde los agresores o "bullies" se sirven de la homofobia, el sexismo, y los valores asociados al heterosexismo (PLATERO, 2007, p. 5).

Dicho en otros términos, el bullying homofóbico resulta ser el acoso de que es víctima un(a) estudiante disidente motivado por su orientación sexual o identidad de género expresado en agresiones físicas, psicológicas o sociales de parte de los pares o docentes contenido en insultos, injurias, agresiones de todo orden, rechazo y en ocasiones la provocación del suicidio (PLATERO; GÓMEZ, 2008).

Los rasgos distintivos del bullying homofóbico son: la invisibilidad por cuanto en muchas ocasiones la agresión permanece inadvertida (o se hace caso omiso de ella), parte de un sistema de violencia estructural fundada 
en la homofobia cultural, estigmatizante no sólo para la víctima sino para todo aquel que se le aproxime pues corre el riesgo de sufrir la misma discriminación, excluyente en el sentido de que toca todos los ámbitos de la vida y no sólo el contexto escolar, los insultos además de permanentes se ciernen sobre la persona en forma de censura y desempoderantes por cuanto las personas agredidas reconocen los atropellos pero se paralizan por temor a que la denuncia exacerbe la homofobia (UNESCO, 2015).

En un intento por dimensionar el problema a nivel nacional el Ministerio de Educación de Chile, desde el año 2009 comienza a registrar las denuncias que se canalizaron a través de una plataforma virtual o en las propias oficinas del Ministerio en todas las regiones de Chile, motivadas por la violencia escolar y, de modo especial, por las denuncias de discriminación.

Este catastro de información sirvió de subsidio a las autoridades educacionales de la época para promover un proyecto de ley de prevención de la violencia escolar, conocido también como ley antibullying (Ley 20.536, 17 de septiembre de 2011).

Uno de los efectos positivos de ese catastro fue que empezaron a aparecer denuncias que remitían a un tipo específico de discriminación. La discriminación motivada por una orientación sexual disidente del orden heteronormativo. Y fue, precisamente, en base a ese catastro oficial entre los años 2009 a 2015 que se analizó la información allí contenida en procura de establecer las causales que originaban la discriminación a juicio de los denunciantes.

\section{Escuela: ¿guardiana del orden} heteronormativo?

Un primer aspecto que se ha de tener en consideración al momento de analizar los efectos que ocasiona la discriminación por orientación sexual e identidades genéricas en contextos escolares es que los discursos y las prácticas sobre sexualidad y género que produce, promueve y difunde la escuela están inspirados en la norma heterosexual (CORNEJO, 2010; BRAGA, 2014). Es decir, a través de la reiteración de los supuestos del orden heterosexual los cuerpos y las identidades son relacionados a un hecho natural y no a una producción social, cultural o pedagógica.

Así lo natural es percibido como aquello que debe ser dominado. Todo aquello que desborda o trasgrede lo natural es catalogado como antinatural o anormal, especialmente cuando la elección de objeto sexual no es funcional a la reproducción de la especie (NÚÑEZ, 2011). Conceptualización que además está revestida con un fuerte contenido moralizante.

En el ámbito educativo esta concepción se materializa a través de una vigilancia rigurosa de los cuerpos y de modo especial de las prácticas disidentes. La reglamentación de la forma de vestir, del maquillaje, la negación del deseo sexual, las cautelas e invisibilizaciones en la educación sexual, la vigilancia de las masculinidades mediante discursos y prácticas homofóbicas, el acoso sexista entre otras medidas represivas tienden a la conservación de la subordinación femenina y la sobrevaloración de la heterosexualidad por sobre cualquier otra expresión de sexualidad (ALONSO; MORGADE, 2008).

Desde muy temprano los niños aprenden que los insultos homofóbicos no sólo sirven para violentar a los que se supone tienen una orientación sexual distinta a la heterosexual o una identidad de género que no es coincidente con el sexo biológico, sino que esos insultos o injurias, de acuerdo a la terminología de Didier Eribón (2001), se constituyen en una pieza clave de la socialización de hombres y mujeres, particularmente de la configuración de las identidades masculina y femenina socialmente esperadas y asignadas.

Se trata de una violencia dirigida a todos los niños, los púberes y los adolescentes (...). Esta violencia contra todos los varones utiliza, frecuentemente, como estrategia pedagógica, 
y como producto mismo de la lógica cultural homofóbica, la violencia física y emocional hacia los niños (...), considerados débiles, afeminados o que no son suficientemente masculinos según los particulares parámetros de género. La violencia contra los afeminados o menos hombres o que en algún momento específico fallaron en el cumplimiento del ideal masculino, se convierten así, en un ejemplo elocuente para los otros niños (...); un ejercicio público de violencia socialmente tolerado que envía un mensaje de amenaza para quienes se atrevan a transgredir el orden de las identidades de género. El cuerpo violentado del otro es la expresión viva de lo que se debe despreciar de uno mismo (NÚÑ̃Z, 2011, p. 87).

Como consecuencia de este proceso pedagógico de socialización, que afecta especialmente a los hombres, hace que la mayoría de los niños aprendan a increpar a los otros. Aprenden que la violencia y la estigmatización son un poderoso mecanismo de poder y de distinción entre los hombres. "Los propios niños se vuelven vigilantes unos de otros, de su propio proceso masculinizador" (p. 88).

De este modo, el orden heteronormativo impone pautas de conducta y roles sociales extremadamente rígidos, especialmente en sociedades más conservadoras. Cualquier trasgresión es severamente sancionada a través de la exposición y ridiculización pública. Este mecanismo disuasivo, que se instala como un dispositivo de autorregulación en los propios sujetos, sobre todo varones, hace que ellos mismos se transformen en guardianes de ese orden, al punto de estar permanentemente no sólo evidenciando su masculinidad expresada en castración de sentimientos o afectos, competitividad y actitudes agresivas, sino también monitoreando permanentemente sus propias conductas por temor a que ellas sean confundidas o mal interpretadas.

Este dispositivo de control se encuadra en lo que Connell (1995) denomina: masculinidades hegemónicas que no es otra cosa que la idealización y valoración exacerbada de ese patrón.

Los hombres jóvenes aprenden que la adopción de formas "femeninas" de comportamiento puede llevarlos al ridículo o a ser estigmatizados $\mathrm{y}$, a veces, desarrollan comportamientos riesgosos con el fin de evitar ser considerados femeninos o afeminados (HERNÁNDEZ; REYBET, 2008, p. 53)

Es decir, la homofobia opera como un mecanismo de control tanto hacia los disidentes del orden heteronormativo, como hacia los propios guardines de ese orden (NÚNEZ, 2011; BRAGA, 2014). Estos dispositivos de control y autocontrol, son resultado de un proceso de normalización de la heterosexualidad (BUTLER, 2002). Proceso mediante el cual la heterosexualidad se convierte en una verdad incuestionable que no deja espacio a otras expresiones erótico-afectivas, pero además contribuye de forma decisiva a la fijación de roles, identidades y modalidades del deseo relegando al rango de antinaturales cualquier otra manifestación de la sexualidad humana, bajo la amenaza de castigo y ostracismo social de aquel que se atreva a transgredir los límites de un orden excluyente.

La homofobia es una característica básica de la heterosexualidad que, además, condiciona el conjunto de la identidad masculina (tanto heterosexual como gay). Homofobia no es tan sólo odiar, temer o estigmatizar a los homosexuales. La homofobia es el miedo y la inseguridad que invade a los varones ante la posibilidad de amar a otros varones. La invención de la heterosexualidad es un modo de controlar ese miedo, condenando la expresión sexual de esos afectos (GUASCH, 2007, p. 131).

En ese contexto una de las funciones fundamentales de la escuela es reprimir a las sexualidades en fuga respecto del ideario 
heteronormativo, especialmente cuando remiten con la formación de varones, al punto de tornarla en obligatoria. No es una opción como sostiene Rich (1980) sino apenas una ilusión de alternativa, puesto que ese orden legitimado por los discursos médicos, jurídicos, psicológicos, religiosos y morales regula tanto las formas de acceder al conocimiento, como los cuerpos y las relaciones de género.

Clave en el proceso de exclusión y silenciamiento de las disidencias y grupos minoritarios son los estereotipos. Basados en creencias producen representaciones sociales estereotipadas mediante las cuales ciertas características son repetidas y taxativamente atribuidas a ciertos individuos considerados como un otro que es reducido a sus supuestas características y a su supuesta naturaleza intrínseca (NÚNEZ, 2011; BRAGA, 2014). En el caso de los homosexuales los estereotipos más recurrentes y socialmente divulgados son aquellos que los representan como personas condenadas a la infelicidad amorosa, volubles, superficiales, promiscuas, obsesivas, entre otras características.

A este respecto Mary Douglas (1976) sostiene que a medida que se procura consustanciar y legitimar la marginación del individuo objetivado como diferente $o$ anómalo, se confiere nitidez al conjunto de los considerados normales.

Se trata parafraseando el texto de Sedgwick (1998) de una pedagogía del closet, que implementa una serie de dispositivos escolares tendientes a invisibilizar y silenciar a los disidentes sexuales (DINIZ, 2013). Así, identidad y silencio parecieran ser las propuestas centrales del discurso sexual escolar.

De alguna manera, la escuela despliega una especie de cerco de inclusión heterosexual (BEER, 2008). Situación que deviene en una forma escondida y secreta de vivir la sexualidad no hegemónica (JOHNSON, 1996), y cuyo correlato en el ámbito pedagógico es la exclusión u omisión de todo conocimiento considerado marginal o abyecto de la estructura formal del currículo.
Así la escuela pasa a ser el espacio del des-conocimiento de saberes e individuos, no permitiendo a los disidentes exponer públicamente sus inclinaciones. En muy contadas oportunidades los estudiantes disidentes pueden asumir sin culpa o vergüenza sus deseos, sobre todo si estos contradicen el orden heteronormativo. En ese escenario las minorías no son verdaderamente incluidas, sino apenas toleradas, imponiéndose una suerte de tolerancia de lo inevitable (CORNEJO, 2014).

Desde el punto de vista pedagógico el currículo escolar se focaliza en el discurso heterosexual, privilegiando la hegemonía masculina y silenciando a las minorías a través de mecanismos de exclusión y deslegitimación. Los efectos de ese discurso refuerzan, además, las oposiciones binarias (masculino / femenino, hombre / mujer, heterosexual / homosexual), la noción de peligro con la consecuente negación del placer y los deseos, y la ausencia de sujetos. Es decir, los estudiantes se convierten en objetos de información sobre sexualidad pero no en sujetos de sexualidades (BRAGA, 2014).

Por otra parte, el silenciamiento curricular de las disidencias puede ser interpretado como currículo nulo, en tanto representa aquello sobre lo cual no se habla ni en la escuela, ni en la formación docente (ALONSO; HERCZEG; ZURBRIGGEN, 2008). Situación que deja en evidencia que la información no es neutra; pues, en tanto se valida y promueve una sexualidad, las otras son silenciadas, invisibilizadas 0 simplemente descalificadas.

No obstante, esos no son los únicos efectos de ese proceso, a través del silenciamiento $\mathrm{u}$ omisión, que no son sino otra forma de violencia (DINIZ, 2011), la escuela condiciona también las elecciones erótico-afectivas de los sujetos. Sus discursos, prácticas, rituales, permisos, prohibiciones crean sentidos, modelan las percepciones y le dan contenido a las historias personales, corporales y sexuales. Esto es, las personas son sujetos escolarizados cuyas marcas escolares permanecen en sus cuerpos al punto de definir sus objetos de valor y de desprecio. 
De este modo, la escuela no sólo tiene la misión de configurar la sexualidad normal (la heterosexualidad), posponiendo su ejercicio para la fase adulta y en el contexto del matrimonio, sino desincentivar y punir cualquier otra configuración o manifestación que escape o atente contra esa normalidad, tolerando, silenciando y naturalizando todas aquellas prácticas discriminatorias que contribuyan a la mantención de ese orden.

Estas paradojas educativas han dado pie a la teoría queer para repensar el sentido mismo del currículo, sus definiciones hegemónicas normalizadoras y masculinizantes, así como sus pretensiones de control de los sujetos más allá de las diferencias y espacios donde habitan. Otro punto de inflexión que escapa a currículo tradicional es la invisibilización de las posibilidades eróticas, del placer corporal, de la emergencia de las fantasías, de los deseos, y en general de todo aquello que individualiza a los sujetos. Para esta teoría el abordaje de las diferencias no forma parte de las preocupaciones escolares; muy por el contrario, los dispositivos escolares tienden hacia la uniformidad y homogeneización de las conductas, deseos y saberes (SILVA, 2001).

Es decir, el ámbito escolar se ha constituido históricamente como el espacio disciplinador, normalizador y reproductor de las desigualdades, motivo por el cual algunos estudiosos afirman que la opresión sexista y homofóbica, definitoria de la heteronormatividad, debería ser considerada una violación de derechos humanos (DINIZ, 2009a).

A este respecto Guacira Lopes Louro (1999) sostiene que, la homofobia es consentida y enseñada en la escuela. Tratos discriminatorios, prejuicios, ofensas, humillaciones, amenazas, menoscabo psicológico, agresiones físicas $\mathrm{y}$ verbales han sido una constante en la vida escolar de muchos estudiantes LGBT. Estos jóvenes desde muy temprano se ven violentados por una pedagogía del insulto, expresada en: bromas, juegos, sobrenombres, insinuaciones, descalificaciones, etc. que se constituyen en un poderoso dispositivo de silenciamiento $\mathrm{y}$ dominación (DINIZ, 2009b).
La escuela se constituye así en un espacio institucional opresivo para muchos sujetos, ya sea por sus prácticas excluyentes y discriminatorias, ya sea por sus omisiones o silenciamiento de esos mismos sujetos.

Desdeesta perspectiva, dadala producción y reiteración de la matriz heterosexista y sus pretensiones normalizadoras que sitúan a los disidentes en las márgenes de la normalidad, se hace necesario no sólo un abordaje amplio y desprejuiciado de la diversidad sexual, sino un cuestionamiento serio de la heteronormatividad y homofobia que confluyen en el espacio escolar, como de las políticas, del currículo y de las prácticas pedagógicas que se plasman en sus discursos y en los procesos de formación de sus agentes educativos; de forma tal, de promover la construcción de una cultura de reconocimiento de la diversidad sexual y del enfrentamiento de la homofobia en las escuelas, en tanto desafío ético y esfuerzo que siente las bases de una auténtica cultura de la paz.

\section{Método}

El presente estudio adoptó una metodología de investigación cualitativa, recurriendo a un enfoque inspirado en la Teoría Fundamentada, el cual es definido como un método que pretende construir teorías explicativas de fenómenos sociales a partir del levantamiento de datos empíricos que son sistemáticamente analizados durante el proceso de investigación (GLASER; STRAUSS, 1967; STRAUSS; CORBIN, 2002; SAN MARTÍN, 2014). En el caso en estudio, análisis de las percepciones y representaciones que subyacen a las denuncias de discriminación por orientación sexual registradas por el MINEDUC en establecimientos educacionales de todo país.

Dado que este estudio se centró en las percepciones subjetivas de los denunciantes, se optó por no ofrecer una definición $a$ priori del fenómeno a estudiar. Por el contrario, la definición quedó abierta a la conceptualización de los denunciantes, como 
una forma de contextualizar su mirada y facilitar su propio discurso.

\section{Participantes}

El estudio está constituido por las 95 denuncias registradas por el MINEDUC en todas las regiones de Chile, en el período 2009 - 2015, concentrándose la mayor parte de ellas en la Región Metropolitana de Santiago $(55,3 \%)$ y en la Región de Valparaíso $(21,5 \%)$. Los denunciantes más recurrentes, de acuerdo a los registros del MINEDUC, son: los apoderados $(38,6 \%)$; los padres / madres de las víctimas $(21,5 \%)$; y los propios estudiantes objeto de la discriminación $(21,4 \%)$.

Desde el punto de vista del género de las víctimas la distribución es la siguiente: mujeres $61,5 \%$ y hombres 38,4\%. Asimismo, el 72,3\% corresponde a estudiantes de enseñanza media y el 27,6\% a enseñanza básica.

\section{Instrumento de recolección de la información}

La información se recolectó en base al registro oficial de denuncias de discriminación por orientación sexual presentada en las secretarias regionales ministeriales del MINEDUC de todo el país, en el período antes señalado. Del catastro nacional de denuncias de discriminación se seleccionó la información referida a discriminación por orientación sexual.

\section{Procedimiento}

La información provino de la base de datos y registros oficial de denuncias de discriminación del MINEDUC. El período seleccionado se explica porque fue a partir del año 2009 que el Ministerio comenzó a registrar toda la información referida a violencia escolary discriminación. Las denuncias están redactadas tal cual las registró el funcionario que las acogió. Los códigos utilizados corresponden al número de la denuncia seguido del párrafo correspondiente (Dn, p.).

\section{Análisis de la información}

El análisis de la información se realizó según el método de comparación continua (STRAUSS; CORBIN, 2002), lo cual se tradujo en procedimientos sistemáticos de codificación con el propósito de sistematizar propiedades e hipótesis acerca del fenómeno en estudio a partir del principio de la saturación teórica (GLASER; STRAUSS, 1967).

La primera fase, de categorización abierta, permitió obtener categorías descriptivas de información a través de un doble proceso de fragmentación y agrupación de los datos provenientes de las denuncias. Luego estas categorías emergentes fueron progresivamente integradas y contrastadas en el proceso de codificación axial, arrojando un total de trece categorías temáticas, que fueron agrupadas y sirvieron de vínculo de los diferentes contenidos relacionados con la pregunta de investigación, que buscaba dilucidar las motivaciones que suscitaron las denuncias. Por último, el proceso de codificación selectiva integró estas categorías principales a partir de una relectura de los datos, obteniéndose un esquema teórico mayor (SAN MARTÍN, 2014).

\section{Resultados}

A continuación, se presentan los resultados obtenidos en las distintas etapas del análisis. En primer lugar, se describen las categorías emergentes que se desprenden de las denuncias y en base a las cuales se esbozaron los análisis relacionales que dieron lugar a dos codificaciones axiales, una de ellas referida a las causales que motivaron la discriminación por orientación sexual en los establecimientos educacionales denunciados y, la otra, a los efectos psico-emocinales, sociales y pedagógicos que ocasionó esa discriminación en las víctimas.

Por último, se presenta la codificación selectiva, que intenta dar cuenta de la discriminación por orientación sexual presente 
en el sistema escolar chileno en el período en estudio, consecuencia directa del heterosexismo y la homofobia que, historicamente, ha derivado en exclusión, invisibilización y represión de las disidencias sexuales en el espacio escolar. Para ilustrar los contenidos se incluyen en el análisis de los resultados algunos extractos literales de las denuncias.

\section{Axial 1- Causales de las denuncias de discriminación por orientación sexual}

En la mayor parte de los casos se puede establecer una relación de causalidad entre las denuncias de discriminación y las medidas disciplinarias adoptadas por los establecimientos educacionales, consideradas arbitrarias o no ajustadas a un determinado proceso en opinión de los denunciantes.

Las medidas pueden ser agrupadas en siete categorías. La primera de ellas, la más recurrente, es la cancelación de matrícula. "El establecimiento habría procedido a la cancelación de matrícula para el año 2012 [...]” (D31, pb). "Apoderada denuncia discriminación de parte del establecimiento educacional. Le cancelan matrícula ( $1^{\circ}$ Enseñanza Media) por condición sexual [...]” (D36, pa). “[...] se le entregaron todos los documentos y debió firmar el retiro" (D29, pc).

En segundo lugar, en consonancia con lo anterior, aparecen las expulsiones sumarias: "Alumna denuncia que Liceo la discriminó por opción sexual, señala que no la han dejado entrar al Liceo se encuentra suspendida y la han amenazado con video que mostraría imágenes con su pareja” (D11, pa). "Mi hija fue expulsada del Liceo porque la vieron dándose un beso con una alumna de $4^{\circ}$ medio" (D20, pa).

En tercer lugar, aparecen las suspensiones provisorias o la condicionalidad de la matrícula. "[...] fue suspendido por el director de este establecimiento por cinco días" (D15, pc). "Condicionalidad extrema para el próximo año de acuerdo a las actuales anotaciones [...]” (D30, pc)
En cuarto lugar, aparece el cierre de año de forma anticipada:

Se presenta apoderado de alumna de $4^{\circ}$ Año de Enseñanza Media, antigua, para dar a conocer que se le cierran año escolar anticipado a contar del 31 de agosto, por su orientación sexual. Por este concepto, el establecimiento determina negarle opción de graduarse, actividades extraprogramáticas contempladas dentro del proyecto educativo. (D47, pa).

Es decir, no sólo se anticipa la licenciatura sino que se establece una suerte de ostracismo escolar motivado por la explicitación de una orientación sexual disidente.

En el quinto lugar, aparece la negación de matrícula como otra de las estrategias de exclusión.

La madre denuncia discriminación hacia su hija, ya que la han dejado sin internado debido a que el establecimiento educacional informa a la madre que su hija tiene una amistad con otra alumna, lo cual no es bien visto a los ojos del Liceo, por lo tanto le han negado la matrícula al internado para el año 2011. (D17, pa).

En sexto lugar, una de las medidas recurrentes es sugerir a los padres retirar a sus pupilos, argumentando que esas comunidades escolares no son apropiadas para sus hijos o recurriendo a amenazas veladas. De ese modo, a los ojos de la autoridad ministerial el establecimiento no aparece cancelando la matrícula o suspendiendo al estudiante, sino que es el propio padre / madre quien voluntariamente lo retira. "La alumna denuncia que su madre fue presionada a retirarla, bajo amenaza de denunciar a la pareja de la alumna” (D12, pa).

Por último, el obligar a un estudiante acusado de homosexualidad a dar exámenes libres es otra de las formas de segregación adoptadas por los establecimientos denunciados. 
A esas medidas se suma la existencia de elementos o contenidos discriminatorios presente en los manuales de convivencia escolar y en otros documentos afines, como son por ejemplo, los proyectos educativos institucionales. Estos elementos se encuentran especialmente presentes en algunos colegios confesionales. "En su manual de convivencia este colegio discrimina a los alumnos con conductas homosexuales impidiéndoseles ser matriculados" (D59, pa). "En los estatutos del establecimiento se prohibe el ingreso de alumnos con tendencia homosexual" (D65, pa).

Cabe subrayar que denuncias de documentación oficial de establecimientos confesionales con contenidos homofóbicos han sido reiterativas por parte de algunas organizaciones LGBT chilenas en la última década.

Sin duda, esas disposiciones no sólo resultan arbitrarias y no ajustadas a las normativas del MINEDUC, que desde hace ya varios años ha venido promoviendo la inclusión sin restricciones de todos los estudiantes al sistema escolar, sino que implican una clara trasgresión de la Ley Antidiscriminación que condena, precisamente:

\section{[...] toda discriminación arbitraria, exclusión o restricción que carezca de justificación razonable, efectuada por agentes del Estado o particulares, [...] en particular cuando se funden en motivos tales como la raza o etnia, la nacionalidad, la situación socioeconómica, el idioma, la ideología u opinión política, la religión o creencia, la sindicación o participación en organizaciones gremiales o la falta de ellas, el sexo, la orientación sexual, la identidad de género, el estado civil, la edad, la filiación, la apariencia personal y la enfermedad o discapacidad" (CHILE, 2012, Art. $2^{\circ}$ ).}

En un segundo nivel de relaciones es posible identificar los componentes de la discriminación, en donde se distinguen claramente a los agentes, conformados básicamente por: directivos, profesores, paradocentes, centros de padres y los compañeros de las víctimas.

No deja de sorprender, de lo que se desprende de las denuncias, que el bullying homofóbico (PLATERO, 2007), que tradicionalmente es definido como la violencia entre pares, en la mayor parte de los casos denunciados proviene inicialmente de los educadores que exponen al escarnio público a los estudiantes disidentes sexuales o que se presume de ello. Y es, precisamente, esa exposición la que desencadena el hostigamiento de los pares, dando lugar a una auténtica pedagogía del insulto (DINIZ, 2009b).

Estrechamente vinculado a lo anterior se reconocen las formas como se expresa la discriminación (insultos, agresiones verbales, malos tratos psicológicos, rumores mal intencionados, interrogatorios en procura de confirmar una identidad disidente y acusaciones de acoso sexual). Todos estos elementos configuran lo que Didier Eribón (2001) caracteriza como la injuria; es decir, aquel estigma que desde muy temprano carga sobre sí el disidente sexual, en tanto dispositivo represor y disuasivo.

Las situaciones paradojales son otros de los detonantes de las denuncias. La primera de ellas alude a la presunción de homosexualidad, esto es, el más pequeño indicio de una sexualidad discordante del ideario heterosexista es motivo de descalificación, ya sea a través de la naturalización de los estereotipos de género (FLEURI, 2006), ya sea a través de la vigilancia de los sexos, particularmente de las masculinidades (TORRÃO FILHO, 2005; NÚÑEZ, 2011).

Estas aprehensiones se tornan más intensas ante actitudes o uso de vestimentas y accesorios considerados indebidos de acuerdo a los patrones de género tradicionales. Es decir, el espacio escolar se convierte así en un entorno de normalización de los estereotipos divulgados a través del currículo oculto (SILVA, 2011).

Otra de las paradojas denunciadas son las expresiones de afecto entre estudiantes 
del mismo sexo. La más leve insinuación de afectividad enciende las alarmas poniendo en marcha los mecanismos disuasivos 0 abiertamente represores de que dispone la escuela. En esta misma línea llama la atención que la discriminación se desencadene no sólo por las actitudes o comportamientos propios, sino también por el entorno que rodea a la víctima. En este caso la discriminación deviene no de una decisión personal sino de la orientación sexual los progenitores, con lo que se confirma que la homofobia circunda no sólo a la víctima, sino se establece un cerco disuasivo sobre todo su entorno (BEER, 2008).

Figura 1- Causales de las denuncias de discriminación por orientación sexual

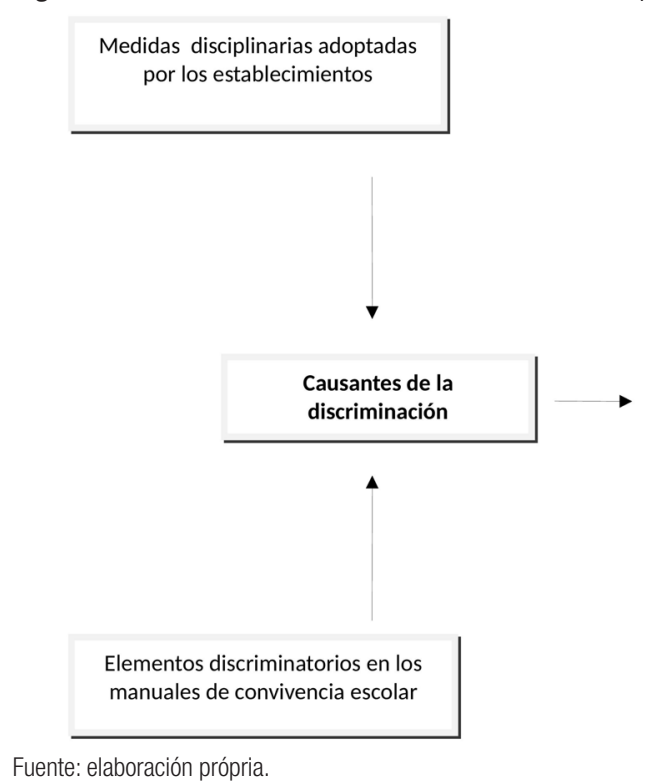

Axial 2- Efectos de la discriminación en las víctimas

Las consecuencias inmediatas que ocasiona la discriminación homofóbica en las víctimas, como se desprende de las denuncias, son una serie de efectos cuyas consecuencias se dejan sentir en los más diversos ámbitos de sus vidas. Esos efectos pueden ser agrupados en cuatro nudos de críticos: psicosomáticos: expresados en malestares físicos, alteraciones del sueño, etc.; psico-emociales: expresados en depresiones, alteraciones de carácter e incluso en intentos de suicidio; sociales: expresados en aislamiento y retraimiento; y académicos: expresados en bajo rendimiento, deserción y reprobación escolar.

Todos estos efectos son coincidentes con lo descrito en la literatura internacional
(POTEAT; STEVEN; ESPELAGE, 2009; RUSSELL et al., 2012; ROBINSON; ESPELAGE; RIVERS, 2013) que caracteriza al fenómeno no solo como un problema de segregación, sino como un grave asunto de salud pública (AERA, 2013).

Es importante señalar que, si bien las denuncias se agruparon en cuatro nudos críticos en razón del estudio, todas ellas están estrechamente ligadas o son consecuancia la una de la otra.

Mi hija fue sometida a interrogatorio de carácter personal por funcionarios del colegio para indagar su orientación sexual [...]. Esto ha significado trastornos de adaptación con síntomas depresivos, motivo por el cual el médico tratante solicitó término del año escolar anticipado. (D52, pa/pb). 
"Alumno que desde el año 2009 a la fecha es agredido verbalmente por sus compañeros, acusándosele de desviación sexual, ha evidenciado alteraciones de su carácter e incluso negatividad de asistir al colegio" (D14, pa/pb).

En el plano estrictamente académico las denuncias subrayan que la persecusión de los disidentes se ha expresado en reprobación de curso y mal rendimiento de las víctimas.

Mi pregunta es la siguiente: ¿Qué nota es 49,9? Bueno para mí es un 5,0. Mi hermana estaba el año pasado en el colegio, y para ellos no es un 5,0 y quedó repitiendo. Bueno ella tiene 17 años y los jóvenes a esa edad están buscando su identidad, buscando su orientación sexual. El colegio en lugar de ayudar a mi hermana comenzó una persecusión por este motivo. (D37, pa/pb).

No obstante, lo que más llama la atención de las denuncias es que sean las propias autoridades de los establecimientos educacionales los que promuevan la segregación de los estudiantes disidentes. "Inspector general dijo a compañeras que no se juntaran con el niño porque era gay, y las que lo hacían eran lesbianas [...]" (D63, pa).

Lo anterior pone de manifiesto que en muchos casos los agentes educativos reafirman aquella idea que los representa como instrumentos de disciplinamiento y normalización de las sexualidades en fuga; pues, estos agentes al legitmar y promover una identidad y desvirtuar, marginar y perseguir a los disidentes sexuales no están sino delineando las fronteras de la normalidad. Es decir, a medida que se procura legitimar la marginación del individuo objetivado como diferente o anómalo, se confiere nitidez a las fronteras del conjunto de los normales (DOUGLAS, 1976).

Con todo, los efectos más graves de la discriminación, como se desprende de una de las denuncias, es el intento de suicidio de una estudiante, que ante los apremios de que es objeto en su colegio, especialmente por parte de las autoridades del mismo que la acusan de bisexualismo, decide antentar contra su vida.

El 31 de octubre siendo las 10,30 me presenté urgente al recinto, ya que, era imposible comunicarmelo por teléfono, mi hija estaba en clases, la llevaron a la dirección por un intento de cortarse las venas. Esto se debe a que me la discrimianron porque ella se declaró bisexual. Me dijeron que ella era una mala influencia, me dijeron que necesitaba tratamiento psiquiátrico y que me la llevara del colegio [...]. (D55, pa).

Los intentos de suicidios de adolescentes LGBT son una realidad que preocupa a los especialistas (AERA, 2013), no sólo porque que en este grupo de la población su incidencia es significativamente más alta, si comparados con otros jóvenes (UNESCO, 2012), sino también porque el intento de suicidio deja al descubierto el silenciamiento e invisibilización de las problemáticas que enfrentan los disidentes sexuales en los espacios escolares, expresado comunmente en bullying homofóbico u otras formas de hostigamiento; además de la falta de preparación de los educadores para manejar y prevenir este tipo de situaciones.

Y hasido, precisamente, el reconocimiento de esa realidad la que ha impulsado a numersos investigadores de distintos países a desarrollar estrategias educativas tendientes a prevenir el bullying homofóbico y proponer innovaciones curriculares que integren estas temáticas en los programas de formación de profesores.

No obstante, la mayor parte de estas propuestas, iniciativas por cierto valiosas y necesarias, además de no ser políticas nacionales en materia de educación sexual, sino más bien complementos o subsidios a las mismas, centran su atención en la prevención o el manejo de situaciones conflictivas motivadas por la homofobia en el espacio escolar sin atacar la raíz del problema, cual es el paradigma heterosexista que genera la homofobia y su régimen de exclusión social. 
Retomando el análisis de los dichos de los denunciantes, no deja de sorprender la actitud de algunos establecimientos, que ante el reconocimiento público de una identidad disidente del orden heteronormativo procuran por todos los medios expulsar al implicado, apelando al mal ejemplo que supone para la comunidad educativa una identidad disidente no autosilenciada. Vale decir, no se condena sólo la presunción de homosexualismo, sino que las iras se desbordan con aquellos que abiertamente deciden romper con las ataduras de una sexualidad impuesta, especialmente cuando ello deviene en expresiones amorosas entre estudiantes del mismo sexo en público: "Mi hija fue expulsada del Liceo porque la dieron dándose un beso con una alumna de $4^{\circ}$ medio" (D20, pa).

Se presenta madre y apoderada de alumno que cursa $5^{\circ}$ de Enseñanza Básica (alumno nuevo), para dar a conocer que el colegio dispone la cancelación de matrícula a contar del 18 de mayo [...], por problemas graves de homosexualismo, sin realizar investigación previa. Por juego besó a compañero de segundo piso. (D10, pa).

En razón de los antecedentes presentados se puede afirmar que los efectos que ocasiona el hostigamiento que acusan las víctimas y las consecuencias que devienen de él, contrariamente a lo que se pudiera pensar, no se origina por el acoso de los pares sino de los directivos y profesores de los establecimientos denunciados. Es más bien el prejuicio e intolerancia de estos últimos, que, a modo de espejo, hace que los pares repliquen conductas discriminatorias e incurran en bullying homofóbico hacia sus compañeros disidentes sexuales.

Figura 2 - Efectos de la discriminación en las víctimas

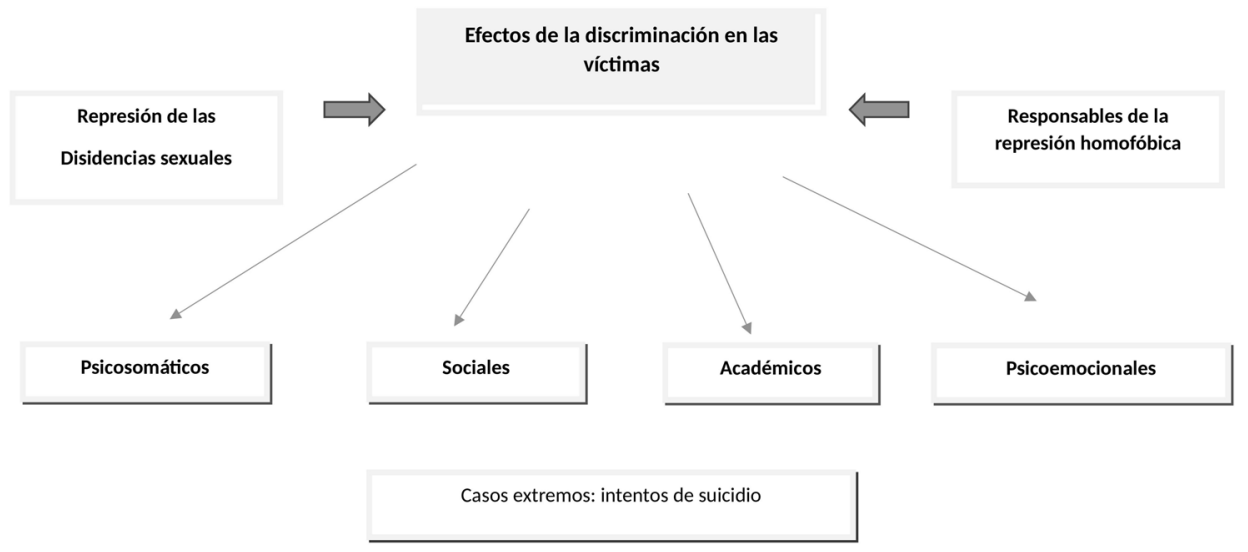

Fuente: elaboración própria.

\section{Análisis selectivo: discriminación por orientación sexual motivada por la homofobia institucional}

El fenómeno emergente central que se desprende del análisis de las denuncias es lo expandido que se encuentra la homofobia en el sistema escolar chileno. Ello en razón de que la información catastrada por el MINEDUC proviene de todas las regiones en el período 2009 - 2015. Con todo, no se puede obviar que la mayor concentración de esas denuncias se localiza en las zonas más pobladas: Santiago y Región de Valparaíso; además que dado el carácter cualitativo del estudio las conclusiones no pueden ser generalizadas a todas las escuelas del país, sino apenas a aquellas que figuran en dicho catastro. 
Desde el punto de vista teórico el contexto de la discriminación homofóbica se funda en el paradigma heterosexista que excluye, reprime, omite y silencia a las sexualidades consideradas disidentes de ese orden. El dispositivo a través del cual se canaliza la exclusión es la homofobia cultural e institucional, la que a su vez se decanta en homofobia escolar, cuyo efecto inmediato es la dificultad del sistema escolar, particularmente de sus agentes educativos, para lidiar con la diversidad sexual; es decir, con todas aquellas sexualidades en fuga que escapan o disienten del ideario heteronormativo. Esto último explicable, probablemente, porque esos agentes son a la vez portadores de la homofobia escolar y productos de una formación heterosexista.

La reacción lógica ante la dificultad para lidiar con la diversidad sexual en el espacio escolar es la represión de las disidencias. Represión que se manifiesta en una serie de mecanismos de disciplinamiento escolar (cancelaciones de matrículas, expulsiones sumarias, matrículas condicionales, vigilancia, etc.).

A su vez los efectos de esa represión devienen, en muchos casos, en bullying homofóbico y en efectos que comprometen los derechos, la integridad y la salud física y mental de las víctimas, que en situaciones extremas puede derivar en intentos de suicidio. Evidentemente la reacción de las víctimas frente a la arbitrariedad de la homofobia escolar es: malestar, resistencia y desconfianza frente al sistema escolar.

En ese contexto las escuelas denunciadas responden a dos premisas. Por una parte, aquellas que siguiendo los enunciados de la teoría de la reproducción sostienen que la escuela es reproductora del orden social, en este caso reproductora de la homofobia cultural fuertemente arraigado en el inconsciente colectivo y consecuentemente en las instituciones que se configuran a partir de ese orden cultural. Y, por otra parte, aquella que representa a la escuela como guardiana del orden heteronormativo $\mathrm{y}$ disciplinadora de las sexualidades en fuga (ALONSO; MORGADE, 2008).

En otras palabras, las escuelas denunciadas parecieran ser tanto el producto de las representaciones y aspiraciones sociales depositadas sobre la institución escolar, como las piezas clave que articulan y ponen en marcha los dispositivos represores y disciplinadores. No obstante, ellas no se agotan en ese mandato, de algún modo representan el sentido y los significados sobre los cuales se configura la escuela a nivel nacional, que en materia de sexualidad y género se horroriza ante la disidencia, especialmente cuando esta reivindica para sí legitimación social-escolar y la posibilidad de expresar y vivenciar, al igual como lo hacen los heterosexuales, sus sexualidades e inclinaciones erótico-afectivas en el espacio escolar.

Figura 3 - Discriminación por orientación sexual en el sistema escolar chileno

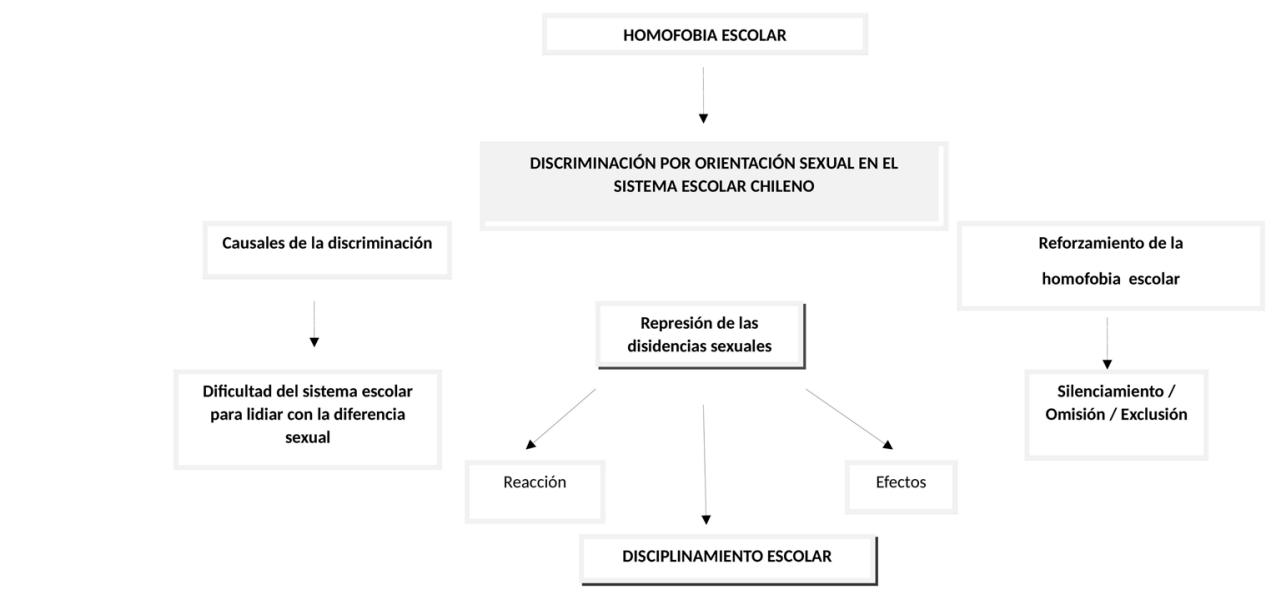

Fuente: elaboración própria. 


\section{Discusión}

En las escuelas denunciadas parecieran confluir, de acuerdo a la información proveniente del MINEDUC, todos los elementos que configuran la homofobia escolar. Por lo pronto, los discursos y prácticas difundidos por esos establecimientos están inspirados en el heterosexismo y una suerte de jerarquización de las sexualidades (BORRILLO, 2001), que establece que en la cima se sitúe la heterosexualidad y por debajo todas las otras sexualidades consideradas abyectas, anormales, patológicas o indeseadas.

Uno de los elementos clave de los dispositivos de control es una vigilancia rigurosa de los disidentes sexuales o que se presume de ello:

A mi hija la están discriminando, y no tan sólo a ella, sino a todos los que tienen una orientación sexual distinta, muchos estudiantes le han dicho a mi hija que el colegio tiene una lista de todos los homosexuales, que hay tanto hombres como mujeres. (D40, pa).

Apoderado denuncia discriminación hacia su hija y otros alumnos por su orientación sexual, que algunos inspectores realizan seguimientos $\mathrm{y}$ tienen listas negras. (D45, pa).

Se ha impedido el acceso y la permanencia en la sala de clases de mi hija, violando sus derechos porque tienen la presunción de una opción sexual, pero mi hija no ha cometido en el establecimiento ninguna conducta que amerite que la aíslen en la biblioteca y que a viva voz le señalen tratamiento psicológico. (D4, pa/pb).

Esa vigilancia se manifiesta de modo especial sobre las masculinidades mediante discursos y prácticas homofóbicas, que pesan tanto sobre los disidentes como sobre los guardianes de ese orden (NÚÑEZ, 2011). "Inspector discrimina al niño porque es más amigo de niñas que niños. Lo acusa de hacer cosas que no corresponde a varones [...]” (D57, pa).

Otra pieza fundamental de ese dispositivo socializador y modelador de las identidades de hombres y mujeres es el insulto (DINIZ, 2009a) y la injuria (ERIBÓN, 2001). Cualquier trasgresión es severamente sancionada a través de la exposición y ridiculización pública.

Es decir, una de las funciones de la escuela es la represión de las sexualidades en fuga respecto del ideario heteronormativo, ya sea a través de la exclusión, ya sea a través del silenciamiento. No obstante, esos no son los únicos mecanismos disuasivos, el espacio escolar históricamente ha evidenciado ser el espacio del des-conocimiento de saberes e individuos, no permitiendo que los disidentes expongan públicamente sus inclinaciones erótico-afectivas.

En este mismo plano se puede afirmar que el currículo nacional con sus invisibilizaciones (no es casual que se omita hablar de diversidad sexual en los planes y programas de educación sexual) pueda ser definido como un currículo nulo, en tanto representa aquello sobre lo cual no se habla en la escuela ni en la formación docente (ALONSO; HERCZEG; ZURBRIGGEN, 2008). Tanto es así, que una de las mayores falencias de la formación de profesores en Chile, sea, precisamente, la falta de preparación de los futuros docentes para abordar temas de sexualidad y lidiar con adolescentes y jóvenes disidentes sexuales.

De este modo, de acuerdo al análisis de las denuncias, se puede afirmar que ellas son bastante ilustrativas de lo que ocurre en muchas escuelas chilenas, no sólo porque la información proviene de todas las regiones del país, sino también porque ratifica el estudio de UNESCO (2012) que sitúa a Chile como el país más homofóbico en el ámbito escolar latinoamericano. En este sentido no es casual tampoco que las propuestas de educación sexual en Chile, en su mayoría, escondan a 
las disidencias sexuales y genéricas, llegando incluso algunas, como fueron denunciadas en su oportunidad, a sostener que la homosexualidad es un trastorno (LA TERCERA, 2012).

Asimismo no se puede obviar, que las denuncias de discriminación por orientación son el correlato de las prácticas y discursos heteronormativos que caracterizan a la heterosexualidad como la auténtica expresión de lo humano. Es decir, el silencio y la censura que predomina en los esablecimientos denunciados, siguiendo a Judith Butler (1997), son formas productivas de poder, pues, se relacionan con la construcción y divulgación de los discursos, y no sólo con su negación y prohibición.

El silencio sobre la diversidad sexual es el reverso de la naturalización de la heteronormatividad, impidiendo o limitando los espacios para que otros sentidos de las sexualidades puedan expresarse. El silencio heteronormativo contiene visiones homofóbicas, excluyentes del mundo, puesto que prioriza los discursos que unen la sexualidad a la reproducción, convirtiendo a la relación heterosexual en la única relación legítima posible.

La negación de los homosexuales en el espacio legitimado de la sala de aula acaba por confinarlos a las bromas y los insultos de los recreos y de los juegos, haciendo de este modo, que jóvenes gays y lesbianas sólo se puedan reconocer como desviantes, indeseados o ridículos (LOUR0, 1998, p. 68) . $^{3}$.

En conclusión se puede afirmar que en un contexto de desinformación y falta de preparación de los agentes educativos, agravada por el descuido de las autoridades educacionales que aún en la Ley 20.845 de Inclusión Escolar (2015) no hacen referencia específica a los grupos discriminados o excluidos de los sistemas escolares formales en razón del sexismo, la xenofobia, el racismo o la homofobia, centrando apenas su atención en los recursos económicos y los criterios de asignación de los mismos a los establecimientos educacionales que acojan a estudiantes vulnerables, no debe sorprendernos las actitudes abiertamente homofóbicas y discriminatorias evidenciadas por algunos establecimientos. Más que situaciones aisladas, las denuncias dejan al descubierto una realidad por largo tiempo silenciada que poco a poco comienza a aflorar, y que no es más que la expresión visible de la homofobia cultural presente en la sociedad chilena.

3- Traducción libre del autor.

\section{Referencias}

ALONSO, Graciela; HERCZEG, Graciela; ZURBRIGGEN, Ruth. Talleres de educación sexual: efectos del discurso heteronormativo. In: MORGADE, Graciela; ALONSO, Graciela (Comp.). Cuerpos, sexualidades en la escuela: de la normalidad a la disidencia. Buenos Aires: Paidós, 2008. p. 251-272.

ALONSO, Graciela; MORGADE, Graciela. Educación, sexualidad, géneros: tradiciones teóricas y experiencias disponibles en un campo de construcción. In: MORGADE, Graciela; ALONSO, Graciela (Comp.). Cuerpos, sexualidades en la escuela: de la normalidad a la disidencia. Buenos Aires: Paidós, 2008. p. 19-39.

AERA. American Educational Research Association. Prevention of bullying in schools, colleges and universities. Washington, DC: AERA, 2013.

BEER, David. Visiones y discursos en la educación física de la escuela primaria, In: MORGADE, Graciela; ALONSO, Graciela (Comp.). Cuerpos, sexualidades en la escuela: de la normalidad a la disidencia. Buenos Aires: Paidós, 2008. p. 149-173.

BORRILLO, Daniel. Homofobia. Barcelona: Ballaterra, 2001.

BRAGA, Denise da Silva. Corpos estranhos se tornam materia: identidades LGBT no currículo da escola. Curitiba: CRV, 2014. 
BUTLER, Judith. Deshacer el género. Barcelona: Paidós, 2012.

BUTLER, Judith. El género en disputa. Buenos Aires: Paidós, 2002.

BUTLER, Judith. Lenguaje, poder e identidad. Madrid: Síntesis, 1997.

CEPESC - Center for Study and Research in Collective Health. Diversity in school. Rio de Janeiro: Cepesc, 2012. Disponible en: <http://www.clam.org.br/uploads/arquivo/Diversity_in_School.pdf>. Acceso en: 30 nov. 2016.

CHILE. Ministerio de Educación. Discriminación en el contexto escolar: orientaciones para promover una escuela inclusiva. Santiago de Chile: Mineduc, 2013. Disponible en: <http://portales.mineduc.cl/usuarios/convivencia_escolar/doc/201309131534370. Discriminacionenelespacioescolar.pdf>. Acceso en: 30 nov. 2016.

CHILE. Ministerio de Educación. Biblioteca del Congreso Nacional de Chile. Ley 20.845 del 8 de junio de 2015: ley de inclusión escolar. Santiago de Chile: Ministerio de Educación, 2015. Disponible en: <https://www.leychile.cl/Navegar?idNorma=1078172>. Acceso en: 30 nov. 2016.

CHILE. Secretaría General de Gobierno. Biblioteca del Congreso Nacional de Chile. Ley 20.609 del 12 de julio de 2012: establece medidas contra la discriminación. Santiago de Chile: Secretaría General de Gobierno, 2012. Disponible en: <http://portales.mineduc. cl/usuarios/convivencia_escolar/doc/201311281730000.LEY-20609_no_discriminacion.pdf>. Acceso en: 30 nov. 2016.

COMISIÓN INTERNACIONAL DE JURISTAS. Principios de Yogyakarta: principios en la aplicación de la ley de derechos humanos internacionales en relación a la orientación sexual e identidad de género. 2007. Disponible en: <http://www.yogyakartaprinciples. org/principles_en.pdf>. Acceso en: 30 noviembre 2016.

CONNELL, Raewyn. Masculinities. Berkeley: University of California Press, 1995.

CONSEJO DE EUROPA. Report on discrimination on grounds of sexual orientation and gender identity in Europe. Paris: Council of Europe, 2011.

CORNEJO, Juan. Bullying homofóbico en Chile: trayectoria histórica. Límite, Arica, v. 9, n. 30, p. 61-70, ago. 2014.

CORNEJO, Juan. Jóvenes en la encrucijada. Última Década, Valparaíso, v. 18, n. 32, p. 173-189, jul. 2010.

DINIS, Nilson Fernandes. Homofobia e educação: quando a omissão também é signo de violência. Educar em Revista, Curitiba, n. 39, p. 39-50, jan./abr. 2011.

DINIZ, Rogéiro. Diversidade sexual na educação: problematizações sobre a homofobia nas escolas. Brasilia, DF: MEC/Unesco, 2009b.

DINIZ, Rogerio. Pedagogía del armario: la normatividad en acción. Revista Retratos de la Escuela, Brasilia, DF, v. 7, n. 13, p. 481-498, jul./dic. 2013.

DINIZ, Rogério. Políticas de educação para a diversidade sexual: escola como lugar de direitos, In: LIONÇO, Tatiana; DINIZ, Débora (Org.). Homofobia \& educação: um desafío ao silêncio. Brasilia, DF: UnB, 2009a. p. 161-193.

DOUGLAS, Mary. Pureza e perigo. São Paulo: Perspectiva, 1976.

ERIBÓN, Didier. Reflexiones sobre la cuestión gay. Barcelona: Anagrama, 2001.

ESPAÑA. Ministerio de Sanidad. Servicio Social e Igualdad. Abrazar la diversidad: propuestas para una educación libre de acoso homofóbico y transfóbico. Madrid: Gobierno de España, 2015. Disponible en: <http://www.inmujer.gob.es/actualidad/ NovedadesNuevas/docs/2015/Abrazar_la_diversidad.pdf>. Acceso en: 30 nov. 2016.

FLEURI, Reinaldo. Políticas da diferença: para além dos estereótipos na prática educacional. Educação \& Sociedade, Campinas, v. 27, n. 95, p.495-520, 2006.

GLASER, Barney; STRAUSS, Anselm. The discocovery of grounded theory: strategies for qualitative research. Chicago: Aldine, 1967. 
GUASCH, Óscar. La crisis de la heterosexualidad. Barcelona: Laertes, 2007.

HERNÁNDEZ, Adriana; REYBET, Carmen. Ruidos y murmullos: las configuraciones discursivas que regulan las prácticas escolares. In: MORGADE, Graciela; ALONSO, Graciela (Comp.). Cuerpos, sexualidades en la escuela: de la normalidad a la disidencia. Buenos Aires: Paidós, 2008. p. 43-64.

JOHNSON, Richard. Sexual dissonances: or the 'impossibility' of sexuality education. Curriculum Studies, United Kingdom, v. 4, n. 2, p. 163-189, 1996. Disponible en: <http://www.tandfonline.com/doi/abs/10.1080/0965975960040202> Acceso en: 10 abr. 2016.

LA TERCERA. Ministro Beyer admite "error" en programas escolares que catalogan la homosexualidad como "trastorno. La Tercera, Santiago de Chile, miércoles, 6 jun. 2012. Disponible em: <http://www.latercera.com/noticia/ministro-beyer-admiteerror-en-programas-escolares-que-catalogan-la-homosexualidad-como-trastorno/> . Acceso en: 15 mzo. 2016.

LOURO, Guacira Lopes. Gênero, sexualidade e educação: uma perspectiva pós-estruturalista. Petrópolis: Vozes, 1998.

LOURO, Guacira Lopes. Pedagogía da sexualidade. In: LOURO, Guacira Lopes (Org.). 0 corpo educado: pedagogías da sexualidade. Belo Horizonte: Autêntica, 1999. p. 07-34.

LOURO, Guacira Lopes, FELIPE, Jane GOELLNER; Silvana Vilodre (Org.). Corpo, gênero e sexualidade: um debate contemporáneo em educação. Petrópolis: Vozes, 2013.

NúÑEZ, Guillermo. ¿Qué es la diversidad sexual? Reflexiones desde la academia y el movimiento ciudadano. Quito: Abya - Yala, 2011.

OLWEUS, Dan. Bullying at the school: what we know and What we can do. Oxford: Blackwell, 1993.

PLATERO, Raquel. jMaricón el último! Docentes que actuamos. Revista D’ estuis de la Violencia, Barcelona, n. 3, p. 5-12, jul./out. 2007.

PLATERO, Raquel; GÓMEZ, Emilio. Herramientas para combatir el bullying homofóbico. Madrid: Talasa, 2008.

POTEAT, Paul; STEVEN, Aragon; ESPELAGE, Dorothy. Psychosocial concerns of sexual minority youth: complexity and caution in group differences. Journal of Consulting and Clinical Phychology. Philadelphia, v. 77, n. 1, p. 196-201, 2009.

PRECIADO, Beatriz. Manifiesto contrassexual. São Paulo: n. 1 Edições, 2014.

RICH, Adriane. La heterosexualidad obligatoria y la existencia lesbiana. Signs: Journal of Women in Culture and Society, Chicago, v. 5, n. 4, p. 631-660, dic. 1980.

ROBINSON, Joseph; ESPELAGE, Dorothy; RIVERS, lan. Developmental trends in peer victimization and emotional distress in LGB and heterosexual youth. Pediatrics, Washington, v. 131, n. 3, p. 423-430, mzo. 2013.

RUSSELL, Stephen et al. Adolescent health and harassement based on dsicriminatory bias. American Journal Public Health, Washington, v. 12, n. 3, p. 493-495, mzo. 2012.

SAN MARTÍN, Daniel. Teoría fundamentada y atlas ti: recursos metodológicos para la investigación educativa. Revista Electrónica de Investigación Educativa, México, DC, v. 16, n. 1, p. 104-122, agt. 2014.

SEDGWICK, Eve. Epistemología del armario. Barcelona: La Tempestad, 1998.

SILVA, Tomaz Tadeu da. Documentos de identidade: uma introdução ás teorías do currículo. Belo Horizonte: Autêntica, 2011.

SILVA, Tomaz Tadeu. Espacios de identidad, In: SILVA, Tomaz Tadeu (Ed.). Las teorías poscríticas. Barcelona: Octaedro, 2001. p. 1-32.

STRAUSS, Anselm; CORBIN, Juliet. Bases de la investigación cualitativa: técnicas y procedimientos para desarrollar la teoría fundamentada. Medellín: Universidad de Antioquía, 2002.

TORRÃO FLLHO, Amílcar. Uma questão de gênero: onde o masculino e o feminino se cruzam. Caderno Pagu, Campinas, n. 24, p. 127-152, jan./jun. 2005. 
UNESCO. El bullying homofóbico y transfóbico en los centros educativos: talleres de sensibilización para su prevención. Santiago de Chile: Unesco, 2015.

UNESCO. Respuestas del sector educación frente al bullying homofóbico. París: Unesco, 2012. (Cuadernillo, 8).

Recibido en: 22.07.2016

Aprobado en: 01.02.2017

Juan Cornejo Espejo es doctor en Ciencia Política y en Estudios Americanos. Licenciado en Ciencias Sociales y profesor de Historia. Académico de la Universidad Católica del Maule, Talca, Chile. 